\title{
Developments of Additive Manufacturing: Local Business and Sustainability
}

\author{
Youhana Masih \\ Department of Mechanical \\ Engineering \\ University of Engineering \& \\ Technology, Lahore-Pakistan \\ Narowal Campus
}

\author{
Saad Zaheer \\ Department of Mechanical \\ Engineering \\ University of Engineering \& \\ Technology, Lahore-Pakistan \\ Narowal Campus
}

\begin{abstract}
Additive manufacturing is a revolutionary process technology. While it has yet to bring about a dramatic transformation of the manufacturing system, there are early signs of how the characteristics of this novel production process can improve resource efficiency and other sustainability aspects as well. Besides sustainability perspectives, AM is also offering a lot of opportunities for local business. AM is unique manufacturing than traditional so researchers *and engineers have improved the developments in this unconventional manufacturing process. This paper is a collection of works in the field of manufacturing technology, business, sustainability and developments. In this paper, experiment has explored the savings of time, energy, cost and usage of materials during additive manufacturing process of products.
\end{abstract}

\section{General Terms}

Additive manufacturing technologies, businesses, sustainability review

\section{Keywords}

Additive manufacturing (AM), local business, sustainability

\section{INTRODUCTION}

The early additive manufacturing (AM) technology was established in $1980 \mathrm{~s}$ as a solution for faster product development. At this hour the technology was called Rapid Prototyping, because the idea was absolutely to produce three dimensional models or mock-ups in order to check form, fit and function. Additive manufacturing is also known as $3 \mathrm{D}$ printing, fast prototyping or freeform fabrication, is 'the process of joining materials to make objects from digital 3D model data, usually layer by layer as opposed to subtractive manufacturing technologies' such as CNC milling. AM is a versatile manufacturing technology. So, there are many potential benefits of AM technology applied to industry sector, such as customized food designs and production [1], personalized medical intricate components (dental crowns and hearing aids), production of complex metal net shape parts for aerospace and defense industries.

Current developments in AM technologies quality and accuracy of products have been improved by developing and researching news sources. Here this paper explores few developments in AM technologies such as hybrid system, properties of materials alloys etc. For example hybrid system is the combination of $\mathrm{AM}$ and subtractive manufacturing (removal process to form geometry of component). This system has enabled to manufacturing final product as it also performs finishing process alongside AM manufacturing.Earlier additive manufacturing technologies were built around materials and alloys that were already available and that had been developed to suit other manufacturing processes. However, the AM processes are somewhat distinctive and properties of these original materials and alloys were far from ideal for these new applications. As properties of alloys materials vary from AM manufacturing processes to conventional manufacturing processes. To overcome this issue, special and lightweight materials have been developed for commercial applications. A variety of materials that have been developed for components of the aerospace and defense sector such as LiBe-Al alloy, $\mathrm{Al}, \mathrm{Mg}$, and AlTi etc [2].

Additive manufacturing is one of these innovative manufacturing technologies. To date AM and sustainable industrial systems have been viewed from different aspects. In this paper has been explored brief the implications of AM on the local business and sustainability of industrial systems. Sustainability addresses about the reuse of plastics, experimental analysis to save materials, energy and time, and other metals materials that do not contribute the production of products because high energy is used for production of powders, generation of these wastes impacts environment sustainability [3].

Furthermore, AM can increase the sustainability of products on environmental and economic level such as less material waste, lightweight products and on-demand manufacturing. In business perspective AM offers many chances for local business because in conventional production, products are based on one design that is produced in large series in a centralized manner. Every consumer gets an identical product with very little space for personal changes, if any. But in AM technologies manufacturer builds the products according to customer's demand at local places as well. In this way every individual can get personalized products at his home through face to face bargaining or online deal. AM is not only producing customized products but also offering many business opportunities. By using these technologies one businessman can develop his own business at his local area.

\section{ADDITIVE MANUFACTURING}

Additive manufacturing (AM) is the process of joining materials to make objects from three-dimensional (3D) digital model data using the layer upon layer method. It is also called layer manufacturing, 3D printing and rapid prototype among engineering and scientific communities. The technique of additive manufacturing builds final shapes by the adding of materials. It has made effective and efficient use of available raw materials and produces least waste with providing adequate accuracy in the geometry of final products.

It easily enables to form final products from 3D CAD data 
without the aid of any additional fixtures and cutting tools [4] AM has some general benefits over conventional manufacturing.

- $\quad$ Less usage of raw materials and energy

- Less impact on environment

- Production and customized products on demands $\mathrm{AM}$ is a modern and disruptive manufacturing technology that has paramount applications for companies and industries at large scale. Currently AM industry is assessed at more than $\$ 3$ billion, with an expected rise to $\$ 13$ billion by 2018 and $\$ 21$ billion by 2020 , companies have used AM to change their business models and logic of creating and capturing value. AM technologies provide not only highly customized and personalized products and production but also a specific set of opportunities and challenges for developing new business models. In this paper, it has been analyzed the few recent developments in AM technologies and explored their applications for manufacturing industry, where they have a large ability to revolutionize the way products are produced

\subsection{The generic $\mathrm{AM}$ process}

The steps of AM process move from the digital CAD data to the tangible product. Various products are manufactured in different ways and different degrees by using AM technologies. AM is manufacturing not only small products for visualization but also large complex products with great engineering content may involve. AM with numerous stages and iterations throughout the production process. In addition, early stages of product development process is merely developed rough parts, with AM being used here because of the speed at which they fabricated. At later stages of the process, parts may need careful cleaning and post-processing before they are used. Here AM is very beneficial because it can create complex products without using special tools. Now it will discuss thoroughly the different stages of the AM process in the form of table in the following eight steps (as illustrated in Fig.1) [6]. [5].
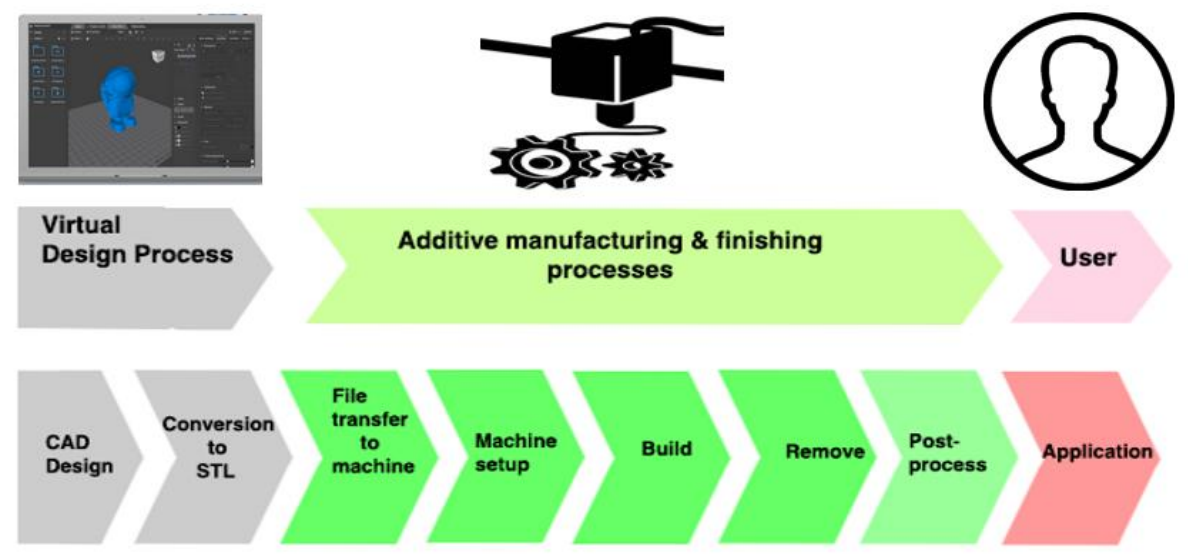

Fig.1 The manufacturing process of AM during production a products Table 1.Table shows the steps of AM process

\begin{tabular}{|l|l|}
\hline $\begin{array}{l}\text { Steps of } \\
\text { AM }\end{array}$ & \multicolumn{1}{|c|}{ Processes } \\
\hline CAD & All complex geometry of parts is designed by 3D modeling software \\
\hline $\begin{array}{l}\text { Conversion } \\
\text { of STL }\end{array}$ & $\begin{array}{l}\text { Designed parts is converted into STL format because AM machine only accept STL } \\
\text { format }\end{array}$ \\
\hline $\begin{array}{l}\text { Transform } \\
\text { STL file to } \\
\text { machine }\end{array}$ & $\begin{array}{l}\text { Holding design STL file of parts is transformed to the machine for further general } \\
\text { manipulation of file like correct size, position and orientation for manufacturing }\end{array}$ \\
\hline $\begin{array}{l}\text { Machine } \\
\text { setup }\end{array}$ & $\begin{array}{l}\text { To set machine properly before the build process as such settings would relate to the } \\
\text { build parameters like the material constraints, energy source, layer thickness, } \\
\text { timings, etc. }\end{array}$ \\
\hline Build & Automatic manufacturing without supervision \\
\hline Removal & After manufacturing final parts is removed from AM machine. \\
\hline $\begin{array}{l}\text { Post- } \\
\text { processing }\end{array}$ & Finishing of parts and removing of extra supports of parts before use \\
\hline Application & Part is ready for use perhaps some painting is required on it according to demand. \\
\hline
\end{tabular}




\section{DEVELOPMENT OF ADDITIVE MANUFACTURING}

There is a rich landscape of technologies and materials available for metals AM. As components in titanium alloys, high-grade stainless steels, nickel alloys, and many others are being produced using electron beam, lasers and arc techniques [7], with a variety of consumable forms. This is a dynamic, constantly evolving field with many researchers and industrial users continually improving the state of the art-work while moving to develop and qualify combinations of material and process (e.g Laser nitrogen treatment) for commercial exploitation [8]. Currently, the number of commercially made parts is low because of the high-performance demands and associated costs for industry to qualify parts. Parts quality costs relate to the demands of the applications and market conditions. Using AM to fabricate metal components opens the possibility for reducing material usage that could enable overall reduction in cost and environment impacts related to manufacturing [9]. As aerospace and defense industries demand not only reduction of required raw materials but also light-weight materials for fabrication of components [10] as AM could also lead to new revolutions for lightweight structures that could see application in UAV (unmanned aerial vehicles).

Currently, properties and quality of part can vary from process to process for a given material and technology. For metals and composites AM is still a relatively new and immature technology. For example copper has high thermal and electrical conductivities which affect the performance of process and reliability during AM process [11]. Researchers and metallurgists have developed new methods to study the properties of materials. Experiments have been performing for the comparison thermal properties of metals and alloys so for. For example, thermal annealing of AL_AM alloy heat exchanger gives the same performance that is equivalent to conventional of Al_6061 heat exchanger [12].

Mechanical properties analysis has been carried out for tensile strength and toughness as a function of material compositions and their improvement as well. Composite of $\mathrm{Si}_{3} \mathrm{~N}_{4}$-based ceramics can be improved by introducing the functionally graded materials concept [13].

A planning of the amalgamation of AM processing with advanced subtractive processing such as milling or turning is another area of technology development that enables mass production of final parts at low cost [14]. Because, plastic products are usually manufactured by injection molding but production costs increase rapidly when the number of parts produced decreases. Therefore, this planning process approach allows a plastic part to be manufactured in a proper way in terms of process capabilities, material consumption, production time with low cost. In addition, commercial conventional manufacturing systems increase the cost of manufacturing along with complexity of products. Therefore, to overcome on this issue hybrid manufacturing system has been developed [15], in which during manufacturing finishing and cleansing process is performed alongside production by using combination of AM technologies and subtractive manufacturing technologies. In market integrating laser directed energy deposition within a precision machining platform offers the capability to add complex features or surfaces to simple base shapes or add to complex shapes in already exiting shapes that have made by $\mathrm{CNC}$ machining. For this application, one such hybrid machine the LASERTEC AM/SM made by DMG Mori, has enabled AM feature conventional and deposition milling within the same setup. Direct energy deposition laser (DED-L) is also using to manufacturing complex geometry structures. Another hybrid systems incorporates a multi-turret milling platform into a powder bed fusion laser (PBF-L) system to mill surfaces and shapes deposited by PBF-L in an attempt to attain the desired accuracy while the part is being built [16].

\section{LOCAL BUSINESS}

A local business structure is one in which a company provides production of goods to local population. Local business enables view the customer's satisfaction [17] by analysis of data from online website at local region. It helps to understand the customer's demand as well. In addition, many companies are using the cloud-based design and manufacturing (CBDM) to get product ideas from ordinary people from diverse locations. CBDM makes reference to a service-oriented networked product development model in which service consumers are able to configure, select and utilize customized product realization resources, services and reconfigure manufacturing systems via Infrastructure-as-a-Service (IaaS), Hardware-as-aService (HaaS), Platform-as-a-Service (PaS) and Software-as-a-Service (SaaS) in response to rapidly changing customer needs [18]. However, these companies are offering these ideas into realistic shapes. Shapeways has been offered 3D printing services over the Internet. Shapeways provides its clients at once access to $3 \mathrm{D}$ printers to build any object whatever they want.

$\mathrm{AM}$ is a versatile technology which has ability to be placed locally next to potential users, up to the point of locating a 3D-printer into a user's home. In the past products are manufactured at centralized site far from the approach of end user as many manufacturers remain constant cost of products by traditional production. Since conventional production needs for special knowledge and costly tools to produce or assemble of intricate products for regular user. Mostly consumers prefer variety of products rather than one type of products but for the customized production increases the cost of products. Moreover, some products need a try-on and rework which results disutility for the consumers.

If this disutility enhances the economies of scale in production, there is scope for local manufacturing at the site of application. This feature is precisely the key of the business model of 3D Hubs. AM has ability to reduce the benefits of traditional economics of scale. As a result, local manufacturing is become profitable. From last five years the price of personal 3D printers has reduced, leading to a growth in the installed base of this machinery of 50-400\% annually. An accessible local manufacturing infrastructure based on AM has happened. Companies like TechShop or nonprofit institutions such as FabLabs offers local access and basic application training of AM. In this way, its users can direct access to local 3D printing resources [19]. Here this novel elaborates few examples for local business.AM has the potential which allows to develop personal business opportunities and enables to manufacture customized production of foods. The food sector is one in every of the key economic sectors in Europe and on the far side and produces nutrition for the world population. Food business contains a distinctive role all countries 
economy because it is important to people lives. In Europe it's the most important producing sector in terms valuable supplemental, turnover and employment. On the opposite hand, many worldwide economic social technological tendencies are pushing organizations to embrace innovation as integrated a part of their company strategy, and to supply customized products tailored to market targets need. For example, Cornell University was made first chocolate [20] by using AM technologies. After this food production, Netherlandsbased has made a research organization which deals with melting extrusion, soft-materials extrusion, liquid binding (PBP) and bioprinting. The Italian food company Barilla and developed a pasta printer around 2013 as well. Moreover, Nestle is making sweet products like chocolate [21]. It can be seen that PepsiCo has making potato chips by using AM technologies to refine production of chips [22]. From this examples, we concluded that all these food items one individual can produce (layer by layer) directly from CAD data at his home or local area by embracing this innovation technology (AM) according to the demand of consumers. The benefits of local production is that it can reduce the time and transport cost as well.

As all children love to have things and can play with them, this toys keep kids entertained and busy. AM business, another area where we can specialize in is the manufacturing of children's toys and selling them. Lego is the top five leading toy industry manufacturers with $5 \%$ of the market [23] is manufacturing toys at lower cost by using AM technologies (3D printing) for small children. There's a very large global market for children's toys and they are always in-demand. So, there is a lot of profit you can generate at your local site. Since there is no prohibition of procreation, that is an assurance that all year round there will be an increase in the demand for these toys especially if you can imagine like a kid and come up with charming designs that will perceive the attention of this small kids.

A very profitable business you can proceed into in this industry is production of jewelry and ornaments, there is an available market for the products especially if they are really beautiful and cheap. The production of very complex jewelry design was challenge Cookson in past Now a days, by using Direct Metal laser sintering (DMLS) goldsmiths of Cookson are manufacturing jewelry of gold on the basis of data provided by CAD software to create a piece layer upon layer [24]. By following this methodology, with the possession of a $3 \mathrm{D}$ printer and a perfect understanding of how to use it, then goldsmith can start his own small business that manufactures fancy cheap but attractive jewelries at local town. Once you can produce hundreds of creative and innovative designs, your printer will readily churn them out in $3 \mathrm{D}$; and you can sell to customers either offline or via the internet.

\section{SUSTAINABILITY}

The development of AM has been made possible by improvements in AM materials and technologies and is being driven by the market factors that necessitate its application such as shorter product development cycles, increasing demand for customized and personalized products (e.g hearing aids, dental crowns, implants, and dentures), increased focus and regulations on sustainability, reduction of manufacturing cost and lead times, and the introduction of new business models and products. This market is assumed to raise to more than $\$ 21$ billion by 2020. AM enables the rapid development of sustainable products and has been growingly used to produce lightweight component structures to save materials and costs of component. This particularly makes better to save a considerable amount of material, energy and cost for the production of one-off or small volume products. Furthermore, the non-processed raw materials can be recycled and re-used by AM to lessen material waste drastically.

\subsection{Product and design process}

Design for Manufacturing and assembly (DfMA) refers to design activity that is based on minimizing the cost of production and development time for a product, while maintaining an appropriate level of quality. A primary strategy in the DfMA involves maximizing the profit of production and analyzes framework for AM applications. AM can process the design of more complex and optimized component, jalong with simpler fewer elements and personalized colored products with a large range of materials [25]. The significant sustainability benefits of AM that can be realized occur over the whole life cycle of the product and its materials, as illustrated in Fig.2. Examples of product development include greater operational functionality, efficiency and durability, and ease of maintenance and manufacturing. In addition, the redesign product has been reduced $25 \%$ weight of fuel nozzle as compared to existing fuel nozzles. This redesign product is achieved by General Electric (GE).

\subsection{Component and product redesign}

A redesign methodology enables the redesigning of an existing part designed for conventional manufacturing into an optimized part designed for AM. The purpose of this procedure is to develop and improve a framework to redesign existing components to exploit AM benefits [26]. For example a missile launcher beam redesigned for additive manufacturing using three different approaches by methods of process-driven shape (to reduce design time and improve design) and designer-driven shape (to lessen cost and mass) [27]. 


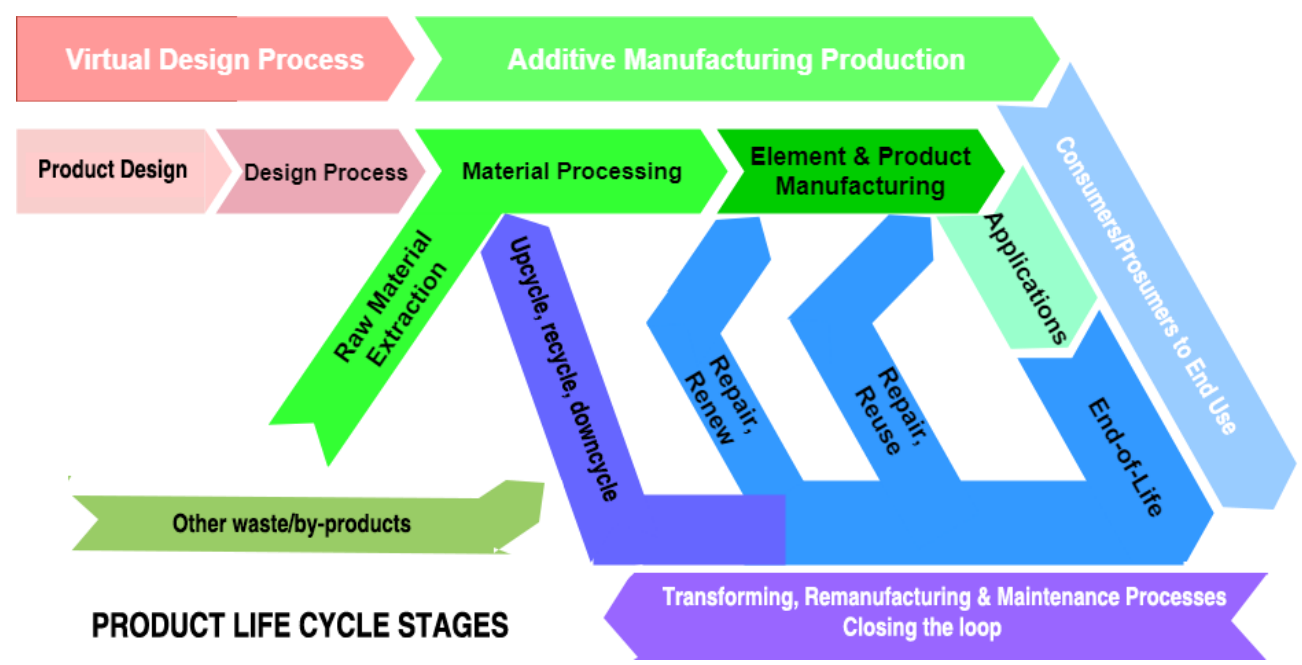

Fig.2 Product and material life cycle for identify sustainability benefits of AM

\subsection{Process redesign}

Just as the product design has been improved, so also improvements can also be to increase the production efficiency. Through AM production components (e.g molds, tools), use only the possible form of the process of production more energy and resources can become effective. AM-based technologies allow to escalate production, aggressively pursue cost reduction or greater efficiency, or prevent components energy dissipated during manufacturing. Designers of Salcomp were capable of redesigning the vent structures of molds so that energy could be dissipated more rapidly. These molds were developed using DMLS AM technology. The main benefit of this redesign was that cooling time was reduced from 14 to 8 s, capable of producing more than 56,000 units each month. Another benefit was the quality improvement, the with rejection rate decreased from $2.0 \%$ to $1.4 \%$ [28].

\subsection{Material input processing}

The raw materials that are used as inputs to AM provide opportunities for sustainability improvements. Similarly, there are several variety of materials are being used as inputs in various types of AM process. The nature of the materials are being used dependent on the specific type of AM process. There are the four major categories of materials (liquid, filament or paste, powder and solid sheet) that are used in AM. The use of raw material is developed layer by layer to form the completed or nearly completed product. Raw material is melted utilizing heat energy produced by a laser, a beam of electrons or a plasma arc as either the energy source or the raw material moves inside a specific AM machine. Initial a threedimensional drawing, through computer aided design (CAD), of the desired product is made. This is then used to create a computer program that gives exact guidelines to automated spatial movements between the melted material being deposited and the inner surface of the AM machine on which the product is being built. As chocolates are the most popular gift, a chocolate additive layer manufacturing (ChocALM) machine has been developed to produce personalized 3D chocolates via layer-upon-Iayer approach. However, conventional chocolate mould method is very expansive to produce highly demanded personalized chocolate by many customers as traditional method requires a specific mould to produce personalised product. ChocALM process can produce economical personalized chocolate at local places without the cost of material use of molding tool [29].

Now a days modern gold processors are getting gold powder directly from gold ore. PTFI (Largest producer of gold and copper) has been using economical methods to produce gold, copper and silver powder directly from gold for manufacturing of jewelry by using AM technologies [30]. During the raw material processing stage, certain raw materials are processed to minimize the resources needed to bring them into an applicable form as inputs for manufacturing processes. Metal powders used in Direct Metal Laser Sintering is required a significant amount of energy for the processing of refining and processing the metal ores in preparation for manufacturing. One UKbased firm Metalysis has commercialized a process for producing titanium powder directly from titanium ore. This process needs significantly not as much energy to produce the titanium powder than Kroll process.

\subsection{Transformation of Post-consumer processes}

Just as a variety of materials can be used as inputs materials in AM technologies, so also can several polymers be recycled as single component thermoplastic filaments, such as high-density polyethylene (HDPE), polylactic acid (PLA), acrylonitrile butadiene styrene (ABS) elastomers as well as composites (e.g. waste wood and carbon fiber reinforced).

Plastic recycling processes have been processed by a recyclebot (a device for converting waste plastic into filament). Various versions of recyclebot have been evolved including open source variations from the Filastruder, Plastic Bank, Lyman, Precious Plastic and Perpetual Plastic, as well as entirely commercial versions including the Filastruder, Filafab, Noztek, Filabot, EWE, Extrusionbot, Filamaker, and the Strooder, Felfil. Most recently, a "RepRapable Recyclebot" has been demonstrated, in which most of the machine's products can be 3-D printed from waste plastic themselves [31].

By mechanical testing, it was found that the recycled PLA had a similar tensile strength to the virgin PLA, with the average being 38 MPA compared to 39 MPA for the virgin. From the study the tensile strength of PLA degraded by about $2 \%$ after the first cycle. It was found that there was little tensile strength difference between the 
recycled PLA and the Virgin PLA that was printed on the Gigabot $\mathrm{X}$ was about $2.5 \%$. The open source Gigabot $\mathrm{X}$ (recycled plastic 3-D printer) was used to fabricate and test the mechanical properties of parts that were built using fused particle fabrication(FPF). During recycling, the main issue is color contamination and a reduction in the material properties of the polymer. The latter issue can be overcome through the use of PLA (as it has ability to be recycled with little quality loss). The conversion of suitable materials and their use for AM is achieved by recycling process. For example, the EKOCYCLE Cube uses recycled polyethylene terephtalate (rPET) in its cartridges with $25 \%$ recycled PET content. Higher recycled content is also possible but limited by the lower aesthetic quality of the resultant polymer. Consequently, recycled plastic and pellets are less expensive than virgin filament for manufacturing. In addition, there is a little difference in the mechanical properties.

Ultimately, AM has been enabled the conversion of postconsumer (which is waste) and byproducts into products. For example, wood flour and dust which are usually byproducts of timber and wood processing. These wood wastes that are commonly used as a filler in thermosetting resins, wood plastic composites and building products. Recently, these by-products have been merged with binding agents to develop a wood filament for AM equipment. A watch manufacturing company that has taken advantage of this latest material input is Bewell Watches which produces customized wood watches.

\subsection{Manufacturing and remanufacturing for maintenance}

$\mathrm{AM}$ in manufacturing process involves building up material layers to make new parts. One huge advantage of using AM technologies in remanufacturing, when one can't obtain that part anymore, he can use 3D printing to make that part. Additional additive manufacturing processes such as 'thermal spraying', welding and 'laser sintering' are used to bring worn parts or cores back to their original dimensions. These worn parts are no longer useful because "their dimensions are all off"; AM techniques builds the core back the original part dimensions. Furthermore, AM technologies can make better existing parts by changing or adding materials to the surface. This technique is also suitable when reman requires complex and small parts [32]. Consequently, AM in remanufacturing enables industries to save energy and materials. 3D damaged solid parts is made by using laser metal deposition (LMD) [33].

Wilson et al. (2014) executed a comparative life cycle assessment between remanufacturing a turbine blade with direct energy deposition (DED) and compared it to manufacturing a new turbine blade. According to the results it depends upon the repair volume which route results in minor environmental impacts. When the repair volume in the turbine blade was $10 \%$ there was approximately $45 \%$ reduction in the associated greenhouse gas emissions and $36 \%$ diminution in energy consumption compared to the manufacture of a new replacing turbine blade [34].

\subsection{Make on demand component and product manufacturing}

With AM technologies customized products can be made according to customer demands. This technology can produce customized products on demand in a way that maximizes production and minimizes costs.

$\mathrm{AM}$ enables products to be manufactured on demand from holding CAD digit design. It can help eliminate or at least minimize inventory waste, reduce inventory risk with no unsold finished goods, while also improving revenue flow as goods are paid for prior to being manufactured. It permits direct interaction between local producers and consumers, collaborative learning, and user revolution. The manufacturing of spare parts on demand is prohibitively very expensive using conventional manufacturing technologies. However, most less cost spare parts can be manufactured from the sharing component 3D CAD files (by customer) by using economics of AM. Kazzata is an online spare parts marketplace \& CAD file repository that provides $3 \mathrm{D}$ CAD files of replacement parts or the replacement component directly from Kazzata to its customers [35]. Just as Kazzata has been producing components on demand, so too has Siemens been manufacturing a variety of components like gas steam and wind turbines, generators and compressors.

\subsection{Closing the loop}
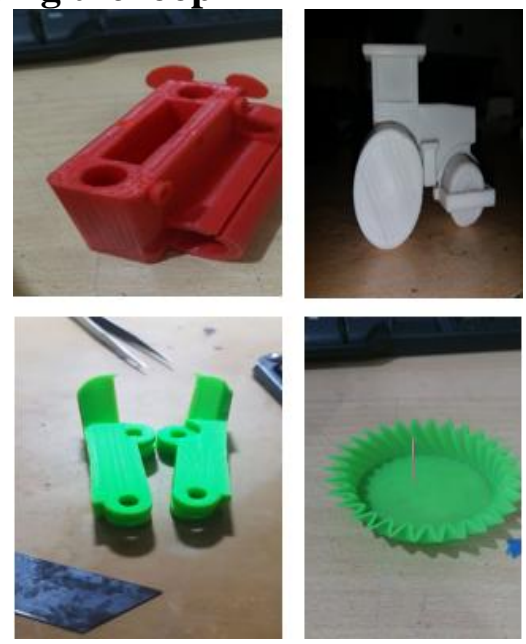

Spare parts can be produced locally on demand during repair, maintenance and manufacturing with lower energy intensity processes. A make to order models can be lessened inventory waste (spare parts). For example Siemens has been manufacturing components for maintenance and repair as well on personal demands. In this way, products not only repair but also they can be upgraded using AM technologies. The repairing, refurbishment and remanufacturing of worn and damaged parts have been possible by DED. Major manufacturing of replacement components on demand can be produced by powder bed fusion (PBF). For example, the production of spare parts of the F-18 Super Hornet fighter jet is being made by AM [36]. Both DED \& PBF methods could have a significant role in enabling circular economy. The diverse stages and scales of AM process have been enabled to achieve closing the loop. During manufacturing in AM unused materials powder can be recycled up to $95 \%-98 \%$. The AM process has the ability to increase the recovery of value embedded in waste.

For example, reusing the plastics like commonly PET used in consumer products and converting them into new style products. This can be achieved with the relatively simple AM apparatus which is accessible to the general public either as products (e.g. EKOCYCLE Cube, Filabot joined to a 3D printer which uses filaments such as the MakerBot) or as services (e.g. 3D Hubs). 
At the product end-of-life stage, in-situ recycling systems can be linked to AM, diverting material from waste streams into new applications. However, in this links material properties issue aforementioned discussed has been found. To get rid of this issue developments and improvement need to enhance the material properties and AM technologies.

\section{EXPERIMENT}

AM technologies have remarkable ability to reuse and reduce raw materials during manufacturing of products against conventional manufacturing. Here in this paper it has been analyze the both manufacturing processes (conventional manufacturing and additive manufacturing) how AM is better than traditional manufacturing processes to decrease use of materials, time and cost of products during manufacturing processes. In this experiment four different or customized products have been separately manufactured (as illustrated in Fig.3) with using AM technologies (SLA \& FDM) and machining processes (CNC machining) to study the case of time, cost and reduction in usage of raw materials

\subsection{Analysis}

After manufacturing customized products, during observation AM has manufactured products at low cost than other convention manufacturing (as show in graph.1 and table.2) as AM is manufacturing customized products at constant price but $\mathrm{CNC}$ machining method increase cost because of tools and power consumption cost. In addition to, CNC machining requires more time during customization production.

Table 2.Table shows price comparison between conventional and unconventional manufacturing

\begin{tabular}{|l|l|l|}
\multicolumn{1}{|c}{ processes } \\
\hline Products & $\begin{array}{l}\text { CNC } \\
\text { machining } \\
\text { price }(\$)\end{array}$ & $\begin{array}{l}\text { AM } \\
\text { process } \\
\text { price } \\
(\$)\end{array}$ \\
\hline Plate & 2 & 2 \\
\hline Strip clips & 3.5 & 2 \\
\hline White roller & 5 & 2 \\
\hline Red slider & 6.5 & 2 \\
\hline
\end{tabular}

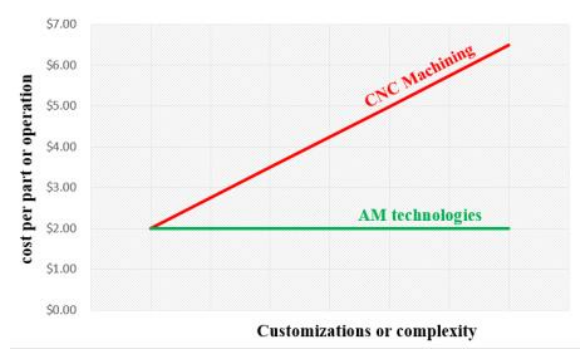

Fig.3 four products manufactured by AM

Graph.1 general comparison cost production between AM and conventional processIn time and usage of raw material, in AM technologies we observed that savings of materials depends on the design or complexity of products during production of products against machining processes. In four products the average savings of materials is in the range 20-60\%. Every product is giving savings of materials according its design in AM process against conventional manufacturing processes. From fore mentioned results, AM is much beneficial than traditional manufacturing because it can allow to manufacture a customized or personalized products at low cost and less material use. Due to the minimizing usage of raw material and energy, AM has cast less impact on environment which leads to it sustainability.

In time measurement analysis, we conclude that during customized production AM is savings average time up to $28 \%$ in the production of fore-mentioned product parts. AM technologies manufacture faster production than conventional manufacturing because convention manufacturing systems have to face tools change and manufacturing processes as well. That's the reason AM can save time during same production of products.

\section{CONCLUSION}

As AM is a versatility ability to manufacture everything whatever a user want to make for his use by layering process. AM process is a unique than conventional process so the properties of materials can be changed during manufacturing process as AM is still immature technology. To overcome this issue, researchers and metallurgists have developed new methods according to the properties of materials in this unique manufacturing process. After this development, hybrid system is another development which has the potential to manufacture whole product.

$\mathrm{AM}$ is opening up new possibilities for local businesses and novel integrated parts designs that can be made using this unconventional technology. By using technology one individual can produce everything at his home. Due to the less usage of raw material, time and energy which leads to reduction of manufacturing cost of lightweight structures products. From experiment analysis it has been concluded that conventional manufacturing manufactures products at high cost because of tools cost and more power consumption during production. Furthermore, AM uses $60 \%$ less raw materials than conventional technology because the savings of materials depends upon the design of products. This quality brings about in the reduction of cost and production of customized products.

\section{ACKNOWLEDGEMENTS}

We thank my partner and others supporters who participate and help to prepare this novel. In this paper, an experiment performed to save the raw materials as compared to conventional production systems.

\section{REFERENCES}

[1] Zhenbin Liu, Min Zhang, Bhesh Bhandari, Yuchuan Wang 3D printing: Printing precision and application in food

[2] Dr Richard Collins and Dr Bryony Core Additive Manufacturing and Lightweight Materials for Aerospace and Defense 2018-2028

[3] Sanjay Kumar, Aleksander Czekanski Roadmap to sustainable plastic additive manufacturing

[4] T.S Srivatsan, T.S Sudarshan Additive Manufacturing Innovations, Advances, and Applications [2-3]

[5] Marcel Bogers, Ronen Hadar, Arne Bilberg Additive manufacturing for consumer-centric business models.

[6] I. Gibson, 1 D. W. Rosen, 1 B. Stucker Additive Manufacturing Technologies Rapid Prototyping to Direct Digital Manufacturing[3-5] 
[7] D. Manfredi, F. Calignano Laser powder bed fusion of aluminum, titanium and nickel based alloys: Materials and design investigations.

[8] S.L. Lin, C.C. Lin, D.Y. Lin, C.S. Chuang Laser Additive Manufacturing Technology in Titanium 64 Implant of Microstructure Fabrication and Analysis.

[9] Olivier Kerbrat, Florent Le Bourhis, Pascal Mognol and Jean-Yves Hascoët Environmental Impact Assessment Studies in Additive Manufacturing.

[10] Dr Richard Collins and Dr Bryony Core Additive Manufacturing and Lightweight Materials for Aerospace and Defense 2018-2028.

[11] F. Singer ; D. C. Deisenroth ; D. M. Hymas ; M. M. Ohadi Additively manufactured copper components and composite structures for thermal management applications.

[12] Tong WU, Andrew A. Wereszczak , Hsin Wang, Burak Ozpineci, Curt W. Ayers Thermal Response of Additive Manufactured Aluminum

[13] Qiang Xue ; Xing Ai ; Jun Zhao ; Yuanyuan Liu ; Yonghui Zhou Analysis of microstructure and mechanical properties of graded nano-composite Si3N4-based ceramic cutting tool material

[14] Z. Zhu ; V. Dhokia ; S. T. Newman A novel process planning approach for hybrid manufacturing consisting of additive, subtractive and inspection processes

[15] V. Brøtan, K. M. Bovie The Hybrid Manufacturing Cell: Determining Key Parameters in the Integration of Powder Bed Fusion with High Speed milling

[16] John O. Milewski Additive Manufacturing of Metals From Fundamental Technology to Rocket Nozzles, Medical Implants, and Custom Jewelry[pp31-31]

[17] Ashwini Kale, Abhijit Joshi A Predictive Business Ranking System: For Local Businesses

[18] Dazhong Wu, David W. Rosen and Dirk Schaefer Cloud-Based Design and Manufacturing

[19] Frank T. Piller, Christian Weller and Robin Kleer Business Models with Additive ManufacturingOpportunities

[20] Harm-Jan Steenhuis, Xin Fang and Tolga Ulusemre Strategy in 3D Printing of Food

[21] nestle 3d printing https://3dprint.com/tag/nestle-3dprinting/

[22] PepsiCo Built a Better Potato Chip with 3D Printing https://all3dp.com/pepsico-built-a-better-potato-chip/ (accessed November 2018)

[23] Emily E. Petersen 1, Romain W. Kidd 2 and Joshua M. Pearce Impact of DIY Home Manufacturing with 3D Printing

[24] Lifestyle Products: Cooksongold - EOS developes Additive Manufacturing technology capable of series production for gold https://www.eos.info/press/customer_case_studies/gli ttering_prospects (accessed October 2018)

[25] M.K. Thompson, G.Moroni T.Vaneker Design for Additive Manufacturing: Trends, Opportunities, Considerations and Constraints

[26] Konstantinos Salonitis, Saeed Al Zarban Redesign Optimization for Manufacturing Using Additive Layer

[27] Sebastian Hällgren , Lars Pejryd Jens Ekengren $(\mathrm{Re})$ Design for Additive Manufacturing

[28] Simon Ford*, M_elanie Despeisse Additive manufacturing and sustainability: an exploratory study of the advantages and challenges

[29] Liang Hao, David Raymond, Giovanni Strano, Sasan Dadbakhsh Enhancing the Sustainability of Additive

[30] PT Freeport Indonesia (PTFI) currently employs two mining methods https://ptfi.co.id/en/how-do-weoperate

[31] Aubrey L. Woern , Dennis J. Byard 1, Robert B. Oakley, Matthew J. Fiedler Samantha L. Snabes and Joshua M. Pearce Fused Particle Fabrication 3-D Printing: Recycled Materials' Optimization and Mechanical Properties

[32] 3D Printing: The Future of Remanufacturing http://www.duxes.cn/eNewsletter/RIF12/en/articles_2 / ( accessed November 2018)

[33] Remanufacturing by 3D Printing of Metals? A Great Potential but Big Challenge http://www.sme.org/MEMagazine/Article.aspx?id=85 89937035\&taxid=1433 (accessed October 2018)

[34] Maija Leino, Joonas Pekkarimen, Risto Soukka, The role of laser additive manufacturing methods of metals in repair, refurbishment and remanufacturingenabling circular economy

[35] Simon Ford, Mélanie Despeisse Additive manufacturing and sustainability: an exploratory study of the advantages and challenges.

[36] Siavash H.Khajavi, JouniPartanen, JanHolmström Additive manufacturing in the spare parts supply chain 